\section{(6) OPEN ACCESS}

\title{
Transfer of patients with ruptured abdominal aortic aneurysm from general hospitals to specialist vascular centres: results of a Delphi consensus study
}

\author{
Robert J Hinchliffe, ${ }^{1}$ Tamsin Ribbons, ${ }^{2}$ Pinar Ulug, ${ }^{3}$ Janet T Powell ${ }^{3}$
}

${ }^{1}$ St George's Vascular Institute, St George's Healthcare NHS Trust, London, UK

${ }^{2}$ Improving Global Health through Leadership

Development Programme, NHS South of England, Winchester, UK

${ }^{3}$ Vascular Surgery Research Group, Imperial College London, London, UK

\section{Correspondence to}

Professor Janet T Powell,

Vascular Surgery, Imperial College, Charing Cross Hospital, Fulham Palace Road, London W6 8RF, UK;

j.powell@imperial.ac.uk

Published Online First 3 July 2012

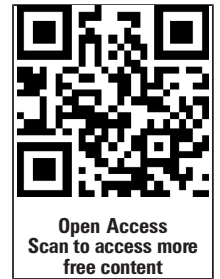

\section{ABSTRACT}

Aim To explore areas of consensus and disagreement concerning the interhospital transfer of patients with a clinical diagnosis of ruptured abdominal aortic aneurysm.

Methods A three-round Delphi questionnaire approach was used among vascular and endovascular surgery and emergency medicine specialists to explore patient characteristics and clinical management issues for emergency interhospital transfer. Analysis is based on 38 responses to rounds 2 and 3 (19 vascular surgeons, 6 interventional radiologists, 13 emergency care specialists) with agreement reported when $70 \%$ of respondents were in agreement.

Results Initially there was agreement that transfer patients should be $<85$ years of age, either alert or with fluctuating consciousness, with moderate or minimal systemic disease, needing no/some help with daily living. Round 3 clarified that patients requiring inotropes and those institutionalised for mental infirmity should be transferred. Those with cardiac arrest in current episode should not be transferred. There was no agreement as to whether those institutionalised with physical infirmities, unconscious/intubated patients or those with severe systemic disease should be transferred. Speed was accepted as important, with agreement for specialty trainees to arrange transfer if consultants were not on site. Consultant-consultant discussion was recommended for patients with severe systemic disease. CT confirmation of diagnosis was considered unnecessary before transfer but ultrasound assessment was desirable, and transfers should not be delayed by waiting for specific tests. There was no agreement about blood tests and ECG before transfer or whether blood should accompany the patient being transferred. There was no agreement as to whether specific staff/facilities needed to be in place at the specialist hospital. A systolic blood pressure $\geq 70 \mathrm{~mm} \mathrm{Hg}$ was sufficient for transfer without the need for intravenous fluids unless deterioration occurred

Conclusions There is broad agreement about the type of patient who should be eligible for transfer but disagreements about patient management before and during transfer remain.

\section{INTRODUCTION}

Vascular surgery is increasingly being practised in large high-volume specialised centres, leaving many hospitals without the ability to manage patients requiring emergency vascular surgery including those with ruptured abdominal aortic aneurysm (rAAA). This often fatal condition commonly presents with symptoms that are not condition- specific, such as back or abdominal pain and collapse. It is most common among elderly patients who often have other comorbidities that may preclude successful repair. In patients requiring interhospital transfer for intervention, speed of transfer is likely to be critical to improving the mortality from ruptured aneurysm. ${ }^{1}{ }^{2}$ This situation provides a dilemma for which there is a lack of current evidence as to which patients should be transferred to a vascular unit, what diagnostic tests are needed before transfer and how patients should be managed during transfer. There is also a need to provide equity of access to treatment for all patients irrespective of geographical location.

In the UK, as in many other countries, there are no guidelines for the transfer of patients with suspected rAAA to specialist vascular centres. The clinical management of these patients usually starts in emergency departments and-if lives are to be saved-is completed by vascular surgeons, often with the help of interventional radiologists if emergency endovascular repair is offered.

This study reports the results of a Delphi consensus among a cohort of specialists in emergency medicine, vascular surgery and interventional radiology which provides a starting point for the future development of guidelines for best practice.

\section{METHODS}

A three-round Delphi questionnaire approach was used, with the second and third rounds being from vascular and endovascular surgery specialists participating in the IMPROVE trial (Immediate Management of the Patient with Rupture: Open Versus Endovascular repair trial; ISRCTN $48334791)^{34}$ and emergency medicine specialists from the Wessex region to explore patient characteristics and clinical management issues for emergency interhospital transfer. The questionnaire was generated from discussion among experts (consultants in emergency medicine $(n=2)$, anaesthesia $(n=1)$, radiology $(n=1)$ and vascular surgery $(n=3)$ who did not participate in the subsequent rounds) and comprised 10 questions with stems (table 1). The second round questionnaire was distributed to the participants in May 2011, who were invited to complete it and provide any specific comments they perceived to be necessary. The results were collated from the first round. Consensus was achieved when $70 \%$ of respondents were in agreement.

A third final round of questionnaires was sent out to the same group of specialists between September and October 2011. The questionnaire 
Table 1 Delphi consensus for interhospital transfer of patients with diagnosis of ruptured abdominal aortic aneurysm: rounds 2 and 3 compared

\begin{tabular}{|c|c|c|c|c|}
\hline & & Round 2 ( $n=38)$ & Round 3 ( $n=29)$ & Frequent comments \\
\hline 1 & Level of requests for transfer & & & \\
\hline a & $\begin{array}{l}\text { Must be assessed by local surgeon (SpR/ } \\
\text { consultant) }\end{array}$ & $23(61 \%)$ & $16(55 \%)$ & Do not delay \\
\hline $\mathrm{b}$ & Consultant-consultant & $17(45 \%)$ & $13(45 \%)$ & \\
\hline c & SpR-consultant & $19(50 \%)$ & $\underline{25(86 \%)}$ & \\
\hline$d$ & $\mathrm{SpR}-\mathrm{SpR}$ & $14(37 \%)$ & $\underline{23(79 \%)}$ & $\begin{array}{l}\text { Do not delay if no } \\
\text { consultant available }\end{array}$ \\
\hline e & Consultant-SpR & $6(16 \%)$ & $17(59 \%)$ & \\
\hline$f$ & No discussion, transfer to vascular unit & $2(5 \%)$ & $3(10 \%)$ & \\
\hline $\mathrm{g}$ & Any grade of doctor & $8(21 \%)$ & $6(21 \%)$ & \\
\hline $\mathrm{h}$ & Nurse/paramedic from ambulance & $11(29 \%)$ & $12(41 \%)$ & \\
\hline 2 & Diagnostic criteria necessary & & & \\
\hline a & Abdominal/back pain and hypotension & $28(74 \%)$ & $21(72 \%)$ & \\
\hline$b$ & Known AAA with symptoms/collapse & $28(74 \%)$ & $21(72 \%)$ & \\
\hline c & In-hospital diagnosis without imaging & $28(74 \%)$ & $20(68 \%)$ & \\
\hline$d$ & $\begin{array}{l}\text { Ultrasound in A\&E with symptoms/ } \\
\text { collapse }\end{array}$ & $21(55 \%)$ & $20(68 \%)$ & $\begin{array}{l}\text { Use should increase } \\
\text { to provide consensus }\end{array}$ \\
\hline e & CT scan any & $18(47 \%)$ & $11(38 \%)$ & \\
\hline$f$ & $\begin{array}{l}\text { CT scan read by } \mathrm{SpR} / \text { consultant } \\
\text { radiologist }\end{array}$ & $13(34 \%)$ & $7(24 \%)$ & \\
\hline 3 & Patient age (years), suitable for transfer & & & \\
\hline a & $<70$ & 13 & $28(97 \%)$ & \\
\hline $\mathrm{b}$ & $<80$ & 15 & $28(97 \%)$ & \\
\hline c & $<85$ & 13 & $10(34 \%)$ & \\
\hline$d$ & $<90$ & $10(26 \%)$ & $6(21 \%)$ & $\begin{array}{l}\text { Consultant-consultant } \\
\text { discussion }\end{array}$ \\
\hline e & No limit & $28(74 \%)$ & $22(76 \%)$ & \\
\hline 4 & Patient condition, suitable for transfer & & & \\
\hline a & Alert and talking & $38(100 \%)$ & $29(100 \%)$ & \\
\hline $\mathrm{b}$ & Obeying commands & $38(100 \%)$ & $29(100 \%)$ & \\
\hline c & Fluctuating consciousness & $31(82 \%)$ & $22(76 \%)$ & \\
\hline$d$ & Requiring inotropes & $23(61 \%)$ & $\underline{22(76 \%)}$ & \\
\hline e & Cardiac arrest in current episode & $9(24 \%)$ & $6(21 \%)$ & \\
\hline$f$ & Unconscious/intubated & $20(53 \%)$ & $14(48 \%)$ & \\
\hline 5 & Patient health before admission if known, & table for transfer & & \\
\hline a & No or minimal systemic disease & $37(97 \%)$ & $29(100 \%)$ & \\
\hline b & Moderate systemic disease & $37(97 \%)$ & $29(100 \%)$ & \\
\hline c & Severe systemic disease & $18(47 \%)$ & $19(66 \%)$ & $\begin{array}{l}\text { Consultant-consultant } \\
\text { referral }\end{array}$ \\
\hline$d$ & Life-threatening systemic disease & $5(13 \%)$ & $4(14 \%)$ & \\
\hline e & Not relevant & $5(13 \%)$ & $5(17 \%)$ & \\
\hline 6 & Patient lifestyle before admission if knowr & uitable for transfer & & \\
\hline a & Independent & $36(95 \%)$ & $29(100 \%)$ & \\
\hline$b$ & Needs some help with daily living & $36(95 \%)$ & $26(90 \%)$ & \\
\hline c & $\begin{array}{l}\text { Dependent on relatives/carers for daily } \\
\text { living }\end{array}$ & $22(58 \%)$ & $20(68 \%)$ & \\
\hline$d$ & $\begin{array}{l}\text { Dependent (eg, dialysis/heart failure/ } \\
\text { home oxygen) }\end{array}$ & $7(18 \%)$ & $6(21 \%)$ & \\
\hline e & Institutional care for physical infirmities & $8(21 \%)$ & $5(17 \%)$ & \\
\hline$f$ & Institutional care for mental infirmities & $15(40 \%)$ & $21(72 \%)$ & \\
\hline g & Irrelevant & $7(18 \%)$ & $4(14 \%)$ & \\
\hline 7 & Tests essential before transfer & & & \\
\hline a & $\begin{array}{l}\text { Ultrasound or CT scan (if diagnosis AAA } \\
\text { not known) }\end{array}$ & $17(45 \%)$ & $14(48 \%)$ & Do not delay \\
\hline $\mathrm{b}$ & Contrast/non-contrast CT & $4(11 \%)$ & $3(10 \%)$ & Do not delay \\
\hline c & CT of whole aorta versus abdominal aorta & $4(11 \%)$ & $2(7 \%)$ & \\
\hline
\end{tabular}


Table 1 Continued

\begin{tabular}{|c|c|c|c|c|}
\hline & & Round 2 ( $n=38$ ) & Round 3 ( $n=29$ ) & Frequent comments \\
\hline$d$ & $\begin{array}{l}\mathrm{FBC} \text { (and } \mathrm{U}+\mathrm{E} / \text { amylase): pancreatitis } \\
\text { issue }\end{array}$ & $14(37 \%)$ & $16(55 \%)$ & Do not delay \\
\hline $\mathrm{e}$ & Cross-match & $13(34 \%)$ & $15(52 \%)$ & \\
\hline$f$ & ECG to exclude acute MI & $21(55 \%)$ & $13(45 \%)$ & Do not delay \\
\hline$g$ & None of the above & $7(18 \%)$ & $5(17 \%)$ & \\
\hline 8 & Maintain blood pressure with fluids & & & \\
\hline a & To systolic $>90 \mathrm{~mm} \mathrm{Hg}$ & $4(11 \%)$ & $4(14 \%)$ & \\
\hline b & To systolic $>70 \mathrm{~mm} \mathrm{Hg}$ & $21(55 \%)$ & $21(72 \%)$ & \\
\hline c & $\begin{array}{l}\text { Travel with blood ( } 0 \text { neg/group specific or } \\
\text { full cross-match) }\end{array}$ & $16(42 \%)$ & $12(41 \%)$ & \\
\hline$d$ & No fluids unless patient deteriorates & $28(74 \%)$ & $26(90 \%)$ & \\
\hline $\mathrm{e}$ & Travel with any available CT film/CD of CT & $27(71 \%)$ & $25(86 \%)$ & $\begin{array}{l}\text { If time available, } \\
\text { transfer electronically }\end{array}$ \\
\hline 9 & Transfer conditions/ambulance and staff & & & \\
\hline $\mathrm{a}$ & Ambulance 999 & $27(71 \%)$ & $28(97 \%)$ & \\
\hline b & Ambulance critical & $11(29 \%)$ & $5(17 \%)$ & \\
\hline c & Ambulance next available & $5(13 \%)$ & $1(3 \%)$ & \\
\hline$d$ & With paramedics only & $16(42 \%)$ & $21(72 \%)$ & \\
\hline $\mathrm{e}$ & With paramedics + nurse & $8(21 \%)$ & $5(17 \%)$ & \\
\hline$f$ & With paramedic + doctor & $8(21 \%)$ & $2(7 \%)$ & \\
\hline $\mathrm{g}$ & $\begin{array}{l}\text { With ATLS (airway control) accredited } \\
\text { personnel }\end{array}$ & $5(13 \%)$ & $5(17 \%)$ & For intubated patients \\
\hline $\mathrm{h}$ & No conditions & $5(13 \%)$ & $5(17 \%)$ & \\
\hline 10 & Essential transfer conditions and staff at $r$ & iving hospital & & \\
\hline $\mathrm{a}$ & Knowledge of ICU bed availability & $4(11 \%)$ & $2(7 \%)$ & \\
\hline $\mathrm{b}$ & $\begin{array}{l}\text { Knowledge of skilled anaesthetist } \\
\text { availability }\end{array}$ & $16(42 \%)$ & $18(62 \%)$ & \\
\hline c & CT scan and radiologist available & $16(42 \%)$ & $18(62 \%)$ & \\
\hline$d$ & Emergency endovascular repair available & $14(37 \%)$ & $14(48 \%)$ & \\
\hline $\mathrm{e}$ & Transfer patient to A\&E resuscitation bed & $24(63 \%)$ & $\underline{25(86 \%)}$ & \\
\hline$f$ & Transfer patient to vascular unit bed & $7(18 \%)$ & 0 & \\
\hline g & Transfer patient to operating theatre/ICU & $22(58 \%)$ & $22(76 \%)^{*}$ & \\
\hline
\end{tabular}

comprised the same questions. Each specialist had access to the second round scores for the whole group and their own personal score, enabling improved evidence for consensus items from the second round. Respondents were invited to score the questions in light of the data from the first round using a Likert scale. The Likert scale (1-4) allowed strongly positive responses to be recorded as 1 and strongly negative responses as 4 , but has no neutral position and forces a choice. In cases where the respondents' new scores differed from the group score, they were invited to comment to ensure the question was correctly interpreted and expose common fallacies.

\section{RESULTS}

In the second round of the Delphi consensus, responses were received from 19 vascular surgeons, 6 interventional radiologists and 13 emergency care physicians. The overall responses to key questions are shown in table 1 . There was good agreement about many of the characteristics of patients to be transferred. Patients eligible for transfer included those $<85$ years of age who were alert and talking or had fluctuating consciousness with minimal or moderate systemic disease. There was no consensus as to whether those either with severe systemic disease or institutionalised for mental infirmities should be transferred. Similarly, there was no consensus as to whether those requiring inotropic support, intubated or unconscious patients should be trans- ferred. There was agreement that patients with a cardiac arrest in the current episode or those institutionalised for physical infirmities should not be transferred.

There was broad opinion and lack of consensus about many of the patient management issues including whether diagnostic tests including imaging and blood tests were required before transfer, at what clinician seniority level patient transfer requests should be made and received, minimal acceptable blood pressure, type of ambulance call and arrangements at receiving hospital (eg, ICU bed or CT availability and endovascular aortic repair capability).

The third round of the Delphi consensus (with responses from 15 vascular surgeons, 2 interventional radiologists and 12 emergency medicine specialists) led to consensus on several issues which are underlined in table 1, as well as many useful comments also reported in table 1 . The important message throughout became 'do not delay', which should override who makes transfer requests and what tests are requested and completed in the referring hospital. Specifically, it became clear that patients institutionalised for mental infirmities and those requiring inotropic support should be eligible for transfer, that a minimum blood pressure of $70 \mathrm{~mm} \mathrm{Hg}$ was acceptable and that all patients should be transferred to an emergency department resuscitation bed or equivalent with a paramedic ambulance crew usually being acceptable. 


\section{DISCUSSION}

There are no national UK guidelines or standard care pathways for the assessment and transfer of patients with rAAA into a specialist vascular centre. The diversity of opinion about essential patient characteristics, diagnostic criteria, referral pathways and transfer conditions was demonstrated clearly in the second round of the Delphi consensus. The participants in this consensus were either clinicians committed to identifying the best interventional management for rAAA (through collaboration in a randomised trial) or emergency care physicians from a single UK region. Hence, across the UK there is likely to be an even more diverse range of opinion about the management of patients with rAAA and, for patients, there is unlikely to be equity of access to specialist vascular centres across the country.

Rupture is nearly always fatal without aneurysm repair. Nevertheless, currently only a minority of patients admitted to hospital with rAAA are offered repair, with evident discrimination against those over 75 years of age and women. ${ }^{5}{ }^{6}$ An older study indicated that patients were more likely to be offered a repair if they were admitted to a major teaching hospital than to a district general hospital. ${ }^{7}$ These observations, together with the diversity of opinion identified in the second round of the Delphi consensus, argue for the development of guidelines to ensure standards of care and equity of patients' access to specialist vascular care.

In the third round of the Delphi consensus there was clear recognition of the importance of speed in diagnosis, referral and transfer, which probably underscored the drive to consensus on several important issues. For instance, consensus was reached that, if rAAA was the most likely clinical diagnosis, delays for confirmatory CT scanning and other tests were unhelpful or even harmful and an immediate referral for transfer should be made. With the diagnosis of abdominal aortic aneurysm becoming one of the core ultrasound imaging competencies acquired by all UK emergency medicine trainees, the confirmation of the presence of an aneurysm by ultrasonography is likely to increase. Again, with the purposes of speed in mind, for many patients this request could be made between registrars in emergency medicine and specialty trainees in vascular surgery, and should not be delayed awaiting a senior general surgical opinion. At the present time, prehospital diagnosis with ambulance crews requesting diversion to a vascular centre was not considered feasible. For patients aged $>85$ years, those with severe systemic disease and some institutionalised patients, emergency medicine consultant to vascular surgery consultant discussion and referral remains the preferred option. If consultants are off site, registrars may have to make the referral.

The need for any specific blood test was thought to be questionable and probably unnecessary in most cases. The issues of blood cross-matching and patient transfers being accompanied by blood products were discussed in a smaller expert group. Since blood sent from one hospital to another hospital is unlikely to be used and ambulance staff are not usually permitted to administer blood products, it seems unnecessary to request a cross-match in the general hospital. If a transfusion has been started, medical staff will be required to accompany the transfer, as they will be if patients are either intubated or require inotropic support. Otherwise, the consensus was that 999 paramedic crews only were sufficient for patient transfer.

Overall, after the three rounds of the Delphi consensus, general agreement had been reached about who should be transferred and referral pathways. There was less agreement about clinical management issues before, during and after transfer. Most of these areas of controversy exist because of a lack of evidence and possibly due to regional differences in service organisation and delivery. The continuing rearrangement of vascular units into larger centres is likely to help standardise care pathways and improve the outcome for patients. There is evidence that largevolume vascular centres offer patients improved survival from emergency repair. ${ }^{8}$ Subgroup analysis from the IMPROVE trial, a large trial of open versus endovascular repair for aneurysm rupture, may indicate patient groups who will have particular benefit from aneurysm repair by either method.

This study has several limitations, including the selection of participants for the Delphi consensus, the lower third round response rate and range of questions included. Nevertheless, the study indicates that, even in the absence of evidence, consensus can be reached on many issues (eg, the transfer of patients institutionalised for mental infirmities or those requiring inotropic support). In the absence of better evidence, the findings from this consensus study could be used as a starting point for the development of interdisciplinary best practice guidelines to improve equity of patient access to care across the UK.

Contributors The study was initiated by RJH and JTP and designed with TR. The study was executed by TR and PU. Analysis was by RJH and JTP. TR and JTP wrote the manuscript. Critical comment and approval of manuscript by all authors.

Funding This project was supported in part by the UK National Institute for Health Research Health Technology Assessment Programme (project 07/37/64). The views and opinions expressed herein are those of the authors and do not necessarily reflect those of the HTA programme, NIHR, NHS or the Department of Health.

\section{Competing interests None.}

Provenance and peer review Not commissioned; externally peer reviewed.

Open Access This is an Open Access article distributed in accordance with the Creative Commons Attribution Non Commercial (CC B-NC 3.0) license, which permits others to distribute, remix, adapt, build upon this work non-commercially, and license their derivative works on different terms, provided the original work is properly cited and the use is non-commercial. See: http://creativecommons.org/ licenses/by-nc/3.0/

\section{REFERENCES}

1. Haveman JW, Karliczek A, Verhoeven EL, et al. Results of streamlined regional ambulance transport and subsequent treatment of acute abdominal aortic aneurysms. Emerg Med J 2006;23:807-10.

2. Salhab M, Farmer J, Osman I. Impact of delay on survival in patients with ruptured abdominal aortic aneurysm. Vascular 2006;14:38-42.

3. Murphy MK, Black NA, Lamping DL, et al. Consensus development methods, and their use in clinical guideline development. Health Technol Assess 1998;2:1-88.

4. Powell JT; IMPROVE Trialists. Time to IMPROVE the management of ruptured abdominal aortic aneurysm. Eur J Vasc Endovasc Surg 2009;38:237-8.

5. Anjum A, von Allmen R, Greenhalgh RM, et al. Explaining the decrease in mortality from ruptured abdominal aortic aneurysm. Br J Surg 2012;99:637-45.

6. Filipovic $\mathbf{M}$, Seagroatt V, Goldacre MJ. Differences between women and men in surgical treatment and case fatality rates for ruptured aortic abdominal aneurysm in England. Br J Surg 2007;94:1096-9.

7. Basnyat PS, Biffin AH, Moseley LG, et al. Mortality from ruptured abdominal aortic aneurysm in Wales. Br J Surg 1999;86:765-70.

8. Holt PJ, Karthikesalingam A, Poloniecki JD, et al. Propensity scored analysis of outcomes after ruptured abdominal aortic aneurysm. Br J Surg 2010;97:496-503. 